\title{
Preocupações de professores de Educação Física ao longo da carreira
}

\section{Physical Education teacher's concerns along the career development \\ Preocupaciones de profesores de Educación Física al largo de la carrera}

\author{
Suelen Vicente Vieira ${ }^{\mathrm{a}, \mathrm{b}, \mathrm{c}}$ (D), Verónica Gabriela Silva Piovani ${ }^{\mathrm{d}}$ (D) , Gelcemar Oliveira Farias ${ }^{\mathrm{e}}$ (D), Jorge Both ${ }^{\mathrm{b}, \mathrm{d}}$ (D)
}

Palavras-chave Mobilidade ocupacional; Educação física; Carreira profissional; Professor.

\section{Keywords}

Career mobility;

Physical education and training;

Professional career; Teacher.

\section{Palabras clave}

Movilidad laboral; Educación y entrenamiento físico; Carrera profesional; Profesor.

\begin{abstract}
RESUMO
O objetivo do estudo foi pontuar as preocupações relacionadas ao exercício da docência dos professores de EF conforme os diferentes ciclos de desenvolvimento profissional. Participaram 20 professores de Educação Física da Educação Básica da cidade de Maringá - PR, sendo a coleta de dados realizada por meio de uma entrevista semiestruturada a qual foi avaliada pela análise de conteúdo. Os resultados demonstraram que os professores com menor tempo de experiência docente eram mais preocupados consigo, ocorrendo a sua diminuição com o avançar da carreira. Os docentes com maior experiência demonstraram preocupações em relação ao desenvolvimento e ao impacto das tarefas realizadas. Conclui-se que os professores eram mais preocupados com o resultado da sua ação pedagógica e com as tarefas que envolvem a prática docente do que com a sobrevivência no ambiente de trabalho.
\end{abstract}

\begin{abstract}
The aim of the study was to analyze the concerns of Physical Education teachers according to the professional development cycles. Data collection was carried out through a semi-structured interview with 20 teachers from Maringá (Brazil), which was evaluated by content analysis. The results showed that teachers with less teaching experience were more concerned with the self-dimension and this concern decreases as their career progressed. Teachers with more experience showed concerns about the development and impact of the tasks performed. It was concluded that the teachers were more concerned with the result of their pedagogical action and with the tasks that involve teaching practice than with the survival in the work environment.
\end{abstract}

\section{RESUMEN}

El estudio analizó las preocupaciones de docentes de Educación Física según los ciclos de desarrollo profesional. Participaron 20 profesores de Maringá (Brasil), siendo aplicada una entrevista semi estructurada, que fue evaluada por medio del análisis de contenido. Los resultados demostraron que los profesores con menor experiencia docente eran más preocupados consigo mismo, ocurriendo una disminución de esa preocupación con el pasar del tiempo de carrera. Los docentes con mayor experiencia demostraron preocupaciones en relación al desarrollo y al impacto de las tareas realizadas. Se concluye que los profesores eran más preocupados con el resultado de su acción pedagógica y con las tareas relacionadas a la práctica docente que con la sobrevivencia en el ambiente de trabajo.

\footnotetext{
aPrefeitura Municipal de Maringá. Maringá, PR, Brasil.

bUniversidade Estadual de Londrina, Programa de Pós-Graduação em Educação Física. Londrina, PR, Brasil.

'Centro Universitário de Maringá, Núcleo de Educação à Distância. Maringá, PR, Brasil.

dUniversidade Estadual do Oeste do Paraná, Centro de Ciências Humanas, Educação e Letras. Marechal Cândido Rondon, PR, Brasil. eUniversidade do Estado de Santa Catarina, Programa de Pós-graduação em Ciências do Movimento Humano. Florianópolis, SC, Brasil.
}

\footnotetext{
*Autor correspondente:

Suelen Vicente Vieira.

E-mail: suelen.vv91@gmail.com
} 


\section{INTRODUÇÃO}

A maneira como o docente se percebe e se sente no ambiente de trabalho é permeado por desafios, dilemas e conquistas (Folle et al., 2008). Esses aspectos vivenciados pelo docente possuem sentidos e significados que provocam responsabilidades e um emaranhado de sentimentos que podem ser expressos em preocupações docentes (Trusz, 2016), por isso a carreira docente institui-se em um contínuo de experiências profissionais/ pedagógicas, as quais promovem uma prática que acarreta na rotina institucionalizada do trabalho (Tardif, 2000).

Quando se trata de preocupações docentes, a Teoria das Preocupações de Fuller (1969) é a referência em estudos sobre essa temática. No intuito de abordar as preocupações que se manifestam em futuros professores, Fuller iniciou a discussão sobre as preocupações docentes durante o curso de formação. Esse estudo evidenciou algumas fases: Pre-Teaching quando o futuro docente ainda está no curso de formação; Early Teaching quando o professor formado ingressa na careira; e, por fim, Late Teaching quando o docente possui experiência com a função desempenhada.

Com o avanço das investigações, Fuller e Bown (1975) identificaram três dimensões de preocupações docentes, sendo que a dimensão Consigo reporta preocupações de sobrevivência dos professores no ambiente escolar, como domínio da turma e convívio com a comunidade escolar. A dimensão Tarefa caracteriza preocupações referentes às tarefas pedagógicas que são designadas aos professores. Na dimensão Impacto da Tarefa os professores demonstram preocupações com os resultados das suas atividades frente aos alunos.

No que se refere às preocupações de docentes de Educação Física (EF) alguns estudos não identificaram a graduação sequencial de preocupações proposta por Fuller (Conkle, 1996; Folle e Nascimento, 2011), evidenciando que professores menos experientes possuíam maiores preocupação com a tarefa (Trusz, 2016), enquanto que outros estudos identificaram que professores iniciantes e com experiência apresentam maiores preocupações com o impacto (Wendt e Bain, 1989; Conkle, 1996). Folle e Nascimento (2011) identificaram que os professores no início da carreira possuíam maiores preocupações com a dimensão tarefa, que se intensificaram no decorrer da prática docente. Entretanto, as preocupações consigo foram mínimas no início da atividade docente e depois de um tempo de experiência foram suprimidas. Assim, todas essas evidências demonstram que diferentes momentos da carreira e contextos de intervenção podem interferir nas preocupações dos professores de EF em relação ao exercício da docência, ocasionando sentimentos diferenciados e situações de ruptura profissional.

Nesse sentido, observa-se que a carreira docente é mediada por sentimentos, motivações, vivências e descontinuidades, sendo que é um elemento que merece destaque ao avaliar as preocupações de professores. Durante a carreira o docente identifica-se e, concomitantemente, constrói seu percurso profissional, expressando sentimentos, criando expectativas e desmistificando crenças. Além disso, ao longo do desenvolvimento profissional os professores são influenciados pelas tensões no ambiente de trabalho, por fatores pessoais, familiares e políticos que interferem na vida profissional e pessoal (Farias et al., 2018).

Os estudos que buscaram estabelecer fases/ etapas na carreira dos docentes avaliaram diferentes características profissionais e pessoais (Sikes, 1985; Nascimento e Graça, 1998; Huberman, 2000; Gonçalves, 2000; Farias et al., 2018). Destaca-se que na realidade brasileira Farias et al. (2018) propuseram o modelo de ciclos de desenvolvimento profissional para os professores de EF, onde foram identificados os ciclos de Entrada (1 a 4 anos), Consolidação das Competências (5 a 9 anos), Afirmação e Diversificação (10 e 19 anos), Renovação (20 e 27 anos) e Maturidade (28 anos ou mais).

Assim, analisar as preocupações dos professores considerando o desenvolvimento da carreira é importante para diminuir problemas que os professores possam sofrer ao longo do trabalho no magistério (Trusz, 2016). No entanto, poucos estudos objetivaram a análise das preocupações conforme os diferentes momentos da carreira docente. Portanto, o objetivo do estudo foi de pontuar as preocupações relacionadas ao exercício da docência dos professores de EF conforme os diferentes ciclos de desenvolvimento profissional.

\section{MÉTODO}

A pesquisa caracterizou-se como descritiva e de abordagem qualitativa. A investigação foi aprovada pelo Comitê de Ética em Pesquisa Envolvendo Seres Humanos da Universidade Estadual de Londrina (parecer 1.664.969).

Participaram da pesquisa 20 docentes de EF vinculados às redes municipal e estadual da cidade de Maringá (Paraná), sendo quatro professores de cada ciclo de desenvolvimento profissional estabelecido por Farias et al. (2018). As características profissionais e pessoais dos participantes da pesquisa são apresentados no Quadro 1.

Na coleta de dados foi utilizada a entrevista semiestruturada. Para isso foi elaborado um roteiro de perguntas baseando-se no modelo teórico de preocupações docentes estabelecido por Fuller e Bown (1975) as quais apresentaram os seguintes indicadores: sobrevivência/atuação no ambiente de trabalho, dificuldades no dia-a-dia escolar, questões burocráticas, convívio com os colegas de profissão, problemas com os alunos, avaliação e observação de suas aulas, apoio administrativo, disciplina e controle de turma, número de alunos por turma, infraestrutura e materiais, tensão no ambiente de trabalho, dificuldades de aprendizagem dos 
Quadro 1. Caracterização dos professores conforme os ciclos de desenvolvimento profissional.

\begin{tabular}{|c|c|c|c|c|c|}
\hline $\begin{array}{c}\text { Características } \\
\text { Sociodemográficas }\end{array}$ & Entrada & $\begin{array}{l}\text { Consolidação das } \\
\text { Competências }\end{array}$ & $\begin{array}{c}\text { Afirmação e } \\
\text { Diversificação }\end{array}$ & Renovação & Maturidade \\
\hline Sujeito & E1/E2/E3/E4 & C1/C2/C3/C4 & D1/D2/D3/D4 & R1/R2/R3/R4 & M1/M2/M3/M4 \\
\hline \multirow{2}{*}{ Sexo } & 3-Feminino $\left(\mathrm{E}^{1,2,4}\right)$ & 3-Feminino $\left(\mathrm{C}^{1,3,4}\right)$ & \multirow{2}{*}{ 4-Feminino $\left(D^{1,2,3,4}\right)$} & 2-Feminino $\left(\mathrm{R}^{3,4}\right)$ & 3-Feminino $\left(\mathrm{M}^{2,3,4}\right)$ \\
\hline & 1-Masculino $\left(E^{3}\right)$ & 1-Masculino $\left(C^{2}\right)$ & & 2-Masculino $\left(\mathrm{R}^{1,2}\right)$ & 1-Masculino $\left(\mathrm{M}^{1}\right)$ \\
\hline \multirow{2}{*}{ Estado Civil } & 3-Solteiro $\left(E^{1,3,2}\right)$ & \multirow{2}{*}{ 4-Solteiro $\left(\mathrm{C}^{1,2,3,4}\right)$} & 3-Solteiro $\left(D^{2,3,4}\right)$ & \multirow{2}{*}{ 4-Casado $\left(\mathrm{R}^{1,2,3,4}\right)$} & 1-Solteiro $\left(\mathrm{M}^{2}\right)$ \\
\hline & 1-Viúva $\left(E^{4}\right)$ & & 1-Casado $\left(\mathrm{D}^{1}\right)$ & & 3-Casado $\left(\mathrm{M}^{1,3,4}\right)$ \\
\hline Idade & 29,5 anos & 29,7 anos & 38,2 anos & 51,7 anos & 52,2 anos \\
\hline \multirow{3}{*}{ Formação Acadêmica } & 2-Mestrado $\left(E^{2,3}\right)$ & 3-Especialização $\left(\mathrm{C}^{1,2,4}\right)$ & 2-Mestrado $\left(D^{1,3}\right)$ & 1-Mestrado $\left(\mathrm{R}^{4}\right)$ & 2-Graduação (M $\left.{ }^{1,4}\right)$ \\
\hline & 2-Graduação $\left(E^{1,4}\right)$ & 1-Graduação $\left(C^{3}\right)$ & 1-Especialização (D²) & 1-Graduação $\left(\mathrm{R}^{1}\right)$ & 2-Especialização $\left(\mathrm{M}^{2,3}\right)$ \\
\hline & & & 1-Graduação (D) & 2-Especialização $\left(R^{2,3}\right)$ & \\
\hline \multirow[t]{2}{*}{ Local de Trabalho } & 2-Rede Municipal $\left(\mathrm{E}^{1,4}\right)$ & $\begin{array}{l}\text { 3-Rede Municipal } \\
\left(\mathrm{C}^{1,3,4}\right)\end{array}$ & 2-Rede Municipal $\left(\mathrm{D}^{1,3}\right)$ & \multirow{2}{*}{$\begin{array}{l}\text { 4-Rede Estadual } \\
\qquad\left(\mathrm{R}^{1,2,3,4}\right)\end{array}$} & $\begin{array}{c}\text { 2-Redes Municipal e } \\
\text { Estadual }\left(\mathrm{M}^{3,4}\right)\end{array}$ \\
\hline & 2-Rede Estadual $\left(E^{2,3}\right)$ & 1-Rede Estadual $\left(C^{2}\right)$ & 2-Rede Estadual $\left(D^{2,4}\right)$ & & 2-Rede Estadual $\left(\mathrm{M}^{1,2}\right)$ \\
\hline \multirow{4}{*}{$\begin{array}{l}\text { Carga Horária de } \\
\text { Trabalho }\end{array}$} & 3-20 horas $\left(\mathrm{E}^{1,2,3}\right)$ & 1-20 horas $\left(C^{3}\right)$ & $1-20$ horas $\left(D^{1}\right)$ & $1-20$ horas $\left(R^{1}\right)$ & 1-20 horas $\left(\mathrm{M}^{4}\right)$ \\
\hline & $1-40$ horas $\left(E^{4}\right)$ & $1-32$ horas $\left(C^{2}\right)$ & 1-28 horas $\left(D^{4}\right)$ & 3-40 horas $\left(\mathrm{R}^{2,3,4}\right)$ & $1-33$ horas $\left(\mathrm{M}^{3}\right)$ \\
\hline & & 2-40 horas $\left(C^{1,4}\right)$ & $2-40$ horas $\left(D^{2,3}\right)$ & & $1-40$ horas $\left(\mathrm{M}^{1}\right)$ \\
\hline & & & & & 1-44 horas $\left(\mathrm{M}^{2}\right)$ \\
\hline \multirow{2}{*}{ Pluriemprego } & 2-Possuem $\left(E^{2,3}\right)$ & 1-Possuem $\left(C^{2}\right)$ & 3-Possuem $\left(\mathrm{D}^{1,2,3}\right)$ & 1-Possuem $\left(\mathrm{R}^{1}\right)$ & 2-Possuem $\left(\mathrm{M}^{1,3}\right)$ \\
\hline & 2-Não possuem $\left(E^{1,4}\right)$ & 3-Não possuem $\left(\mathrm{C}^{1,3,4}\right)$ & 1-Não possuem $\left(D^{4}\right)$ & 3-Não possuem $\left(\mathrm{R}^{2,3,4}\right)$ & 2-Não possuem $\left(\mathrm{M}^{2,4}\right)$ \\
\hline \multirow{4}{*}{ Tempo de Carreira } & 1 ano e 3 meses $\left(E^{1}\right)$ & 7 anos $\left(\mathrm{C}^{1}\right)$ & 16 anos $\left(D^{1}\right)$ & $25 \operatorname{anos}\left(R^{1}\right)$ & $32 \operatorname{anos}\left(\mathrm{M}^{1}\right)$ \\
\hline & 1 ano e 8 meses $\left(E^{2}\right)$ & 6 anos $\left(C^{2}\right)$ & 11 anos $\left(D^{2}\right)$ & 23 anos $\left(R^{2}\right)$ & 29 anos $\left(\mathrm{M}^{2}\right)$ \\
\hline & $3 \operatorname{anos}\left(E^{3}\right)$ & 5 anos e meio $\left(C^{3}\right)$ & 11 anos $\left(D^{3}\right)$ & 25 anos $\left(R^{3}\right)$ & 28 anos $\left(\mathrm{M}^{3}\right)$ \\
\hline & 4 anos $\left(E^{4}\right)$ & 5 anos $\left(C^{4}\right)$ & $12 \operatorname{anos}\left(D^{4}\right)$ & 21 anos $\left(R^{4}\right)$ & 38 anos $\left(\mathrm{M}^{4}\right)$ \\
\hline
\end{tabular}

Fonte: Os autores.

alunos, motivação dos alunos, planejamento, avaliação, além de apresentar uma pergunta auxiliar buscando identificar novos indícios de preocupações docentes. As entrevistas foram realizadas nas escolas onde os professores eram lotados e tiveram a duração total de 864 minutos, obtendo a média de 43,2 minutos por entrevista. Após a transcrição, as entrevistas foram encaminhadas aos docentes, para a validação do conteúdo, para ampliar ou subtrair alguma informação do conteúdo das entrevistas, sendo que sete professores realizaram esta solicitação enquanto os demais permaneceram com o constructo da fala inicial.

As entrevistas foram analisadas de acordo com a técnica da análise de conteúdo, seguindo as orientações de Bardin (1977). Para este momento obedeceu-se as seguintes etapas: pré-análise, que inclui a organização dos dados da pesquisa, momento em que fez-se a organização do material a ser analisado, de modo a compreender as preocupações dos docentes no seu tempo de desenvolvimento profissional; a exploração do material, caracterizada pela definição por parte dos pesquisadores dos percursos a serem realizados na pesquisa para a análise dos dados; e o tratamento dos dados da pesquisa, no qual os pesquisadores, por meio da inferência e interpretação dos resultados analisam os significados e a autenticidade dos dados. Destaca-se que uma avaliadora realizou a leitura da transcrição das entrevistas para verificar possíveis erros no texto ou incongruências, e outros dois pesquisadores realizaram uma avaliação crítica dos dados coletados por meio das entrevistas.

Por fim, destaca-se que as categorias de análise foram estabelecidas a priori, baseadas na Teoria das Preocupações dos docentes, as quais abordavam as dimensões: Consigo, Tarefa e Impacto da Tarefa (Fuller e Bown, 1975). Entretanto, subcategorias das dimensões foram determinadas a posteriori por meio da análise do conteúdo das informações apresentadas nas entrevistas.

\section{RESULTADOS E DISCUSSÕES}

No intuito de pontuar as preocupações dos docentes de EF conforme os ciclos de desenvolvimento profissional, os dados foram apresentados considerando as dimensões de preocupações evidenciadas na Teoria de Fuller e Bown (1975) e, a partir de cada dimensão a análise pormenorizada em cada ciclo de desenvolvimento profissional na perspectiva de trazer subsídios para a carreira docente. Na dimensão Consigo foram evidenciados preocupações referentes a indisciplina, controle de turma, ser avaliado; na dimensão Tarefa os docentes demonstraram preocupações frente ao planejamento, avaliação, número de alunos por turma, infraestrutura e materiais e questões burocráticas; e por fim, na dimensão Impacto da Tarefa as preocupações permearam a falta de um ensino individualizado, a motivação dos alunos, identificação das dificuldades/ necessidades de aprendizagem e o resultado do ensino para o aluno. 


\section{DIMENSÃO CONSIGO}

Ao analisar as preocupações Consigo dos docentes de $\mathrm{EF}$, foram identificadas inquietudes frente: ao sentimento de se sentir avaliado durante a regência de aulas pelos demais colegas de trabalho, pela família, equipe diretiva e demais integrantes da comunidade escolar (E1/E2/ $\mathrm{E} 3 / \mathrm{C} 2 / \mathrm{C} 3 / \mathrm{R} 3 / \mathrm{R} 4 / \mathrm{M} 2$ ); o controle de turma (E1/E2/C1/ C2/C4/R3); a indisciplina (E1/E2/C3/C4/D4/R3/M2). No entanto, foi perceptível que metade dos participantes do estudo não demonstrou preocupações referentes a essa dimensão. Ressalta-se que os professores vinculados ao ciclo de entrada apresentaram maior propensão para as preocupações dessa dimensão quando comparados com os demais ciclos (Quadro 2).

Alguns estudos apontaram que no início da carreira ou durante o estágio supervisionado obrigatório os professores/estudantes apresentam preocupações relacionadas à sobrevivência no ambiente de trabalho (Fuller, 1969; Tankersley, 2010). No entanto, observa-se que a preocupação consigo diminuiu com o decorrer da carreira docente (Costa, 2013; Vieira et al., 2018).

Destaca-se que temas como o controle de turma e sentimento de ser avaliado pelos demais colegas de trabalho, pela família, equipe diretiva e demais integrantes da comunidade escolar, se sobressaíram nos dois primeiros anos da carreira. No contexto brasileiro, resultados semelhantes foram encontrados por Costa (2013) e Favatto e Both (2019), nos quais os professores dos primeiros anos de docência demonstram maiores preocupações com o domínio de turma e o sentimento de ser observado e avaliado durante as suas aulas. No contexto internacional, na dimensão consigo evidenciou-se inquietações de professores relacionadas ao impacto com a realidade de trabalho (Tankersley, 2010).

No ciclo de diversificação da carreira, constatou-se que os docentes apresentaram poucas preocupações. Isso pode ser explicado por meio das características do próprio ciclo, em que os docentes manifestam domínio da rotina básica no ambiente escolar, partilham experiências e conhecimentos com os demais colegas de trabalho (Farias et al., 2018). Em complemento, nesse período da carreira os professores encontram-se na fase de estabilização, e estabelecem uma rigidez pedagógica (Huberman, 2000). De fato, durante essa etapa da vida docente há uma estabilização que provoca autoconfiança,

Quadro 2. Indicadores da dimensão Consigo.

\begin{tabular}{|c|c|c|}
\hline Indicadores & Ciclos & Exemplos de relatos \\
\hline \multirow{5}{*}{$\begin{array}{l}\text { Sentimento de } \\
\text { se sentir avaliado } \\
\text { durante a } \\
\text { regência de aulas }\end{array}$} & Entrada & $\begin{array}{l}\text { Se por alguma razão eu sinto que a pessoa realmente quer contribuir com as minhas } \\
\text { aulas e vem uma crítica pertinente eu gosto disso. Agora eu não gosto quando estou } \\
\text { sentindo perseguição (E3) }\end{array}$ \\
\hline & Consolidação & $\begin{array}{l}\text { Eles (supervisores) sempre aparecem de surpresa, não só para mim [...]. Por que o olhar } \\
\text { não é colaborativo, o olhar é realmente voltado para avaliação mais punitiva (C3) }\end{array}$ \\
\hline & Diversificação & 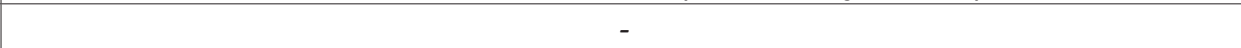 \\
\hline & Renovação & $\begin{array}{l}\text { Acho que todo mundo se preocupa com a nossa performance enquanto professores. Nós } \\
\text { então de EF, que só trabalha em local aberto, todo mundo olha. (R4). }\end{array}$ \\
\hline & Maturidade & $\begin{array}{l}\text {...através da avaliação deles, eu vejo o que eu não estou atingindo ainda. Se eu escuto } \\
\text { que ele tem a me dizer, eu encontro estratégias pra alcança-lo, então, a avaliação é } \\
\text { fundamental (M2). }\end{array}$ \\
\hline \multirow{5}{*}{$\begin{array}{l}\text { Controle de } \\
\text { turma }\end{array}$} & Entrada & $\begin{array}{l}\text { Controle na sala de aula a gente vai adquirido com tempo, na verdade criando alguns } \\
\text { métodos diferenciados. Mas às vezes penso: 'será que eu tô agindo certo, será que eu } \\
\text { poderia ser muito melhor' (E2). }\end{array}$ \\
\hline & Consolidação & $\begin{array}{l}\text { Gosto de manter o controle dos meus alunos, ter uma disciplina, minhas regras com a } \\
\text { turma, e gosto de manter disciplina pra conseguir executar o meu trabalho... (C1). }\end{array}$ \\
\hline & Diversificação & - \\
\hline & Renovação & $\begin{array}{l}\text { Procuro não gritar, não sair do limite e conversar com eles. Quando eu vejo que o } \\
\text { trabalho não vai fluir, eu paro espero eles se acalmarem para continuar (R3). }\end{array}$ \\
\hline & Maturidade & - \\
\hline \multirow{5}{*}{ Indisciplina } & Entrada & $\begin{array}{l}\text { A indisciplina dos alunos é muito difícil por que o professor prepara a sua aula, e chega } \\
\text { na sala, o aluno te xinga, bate de frente, tem casos de violência. [...]. É muito difícil } \\
\text { porque o aluno não prejudica só ele, prejudica uma turma inteira, você e o seu trabalho } \\
\text { (E1). }\end{array}$ \\
\hline & Consolidação & $\begin{array}{l}\text { É muito tempo da aula tentando fazer eles se acalmarem, fazer com que eles parem de } \\
\text { se bater, de brigar. (C4). }\end{array}$ \\
\hline & Diversificação & $\begin{array}{l}\text { Olha, eu ainda brinco com os outros professores que tenho recurso, tiro aula prática } \\
\text { [risos]. Então dessa forma eu consigo dar uma controlada melhor neles [alunos], mas ao } \\
\text { mesmo tempo eu me vejo podando (D4). }\end{array}$ \\
\hline & Renovação & Tem dia que a gente não consegue, que a gente sai do plumo um pouco (R3). \\
\hline & Maturidade & Claro, aluno tem que ter disciplina, é à base da aprendizagem (M2). \\
\hline
\end{tabular}

Fonte: Os autores. 
comprometimento e força de vontade (Sikes, 1985; Ferreira, 2008).

O fato de os professores do ciclo de renovação apresentarem maior intensidade com as preocupações da dimensão consigo pode ser explicado pelas próprias características dos docentes. Nesse momento da carreira, alguns professores mostram-se preocupados com a docência e atribuem a ela algo que ainda requer investimento pessoal (Farias et al., 2018). Além disso, alguns professores podem mostrar interesse pelo seu local de trabalho, pelos discentes, e anseiam por dar continuidade aos estudos (Gonçalves, 2000).

Ao final da carreira docente, apesar de apresentar preocupações consigo, as inquietudes dos professores estão atreladas a questões pedagógicas que objetivam auxiliá-lo no trato com o aluno, como, a avaliação que os alunos fazem das aulas. De fato, as autopreocupações são mais presentes no início da carreira, as quais são acometidas pelo impacto com a realidade do trabalho (Tankersley, 2010).

\section{DIMENSÃO TAREFA}

As preocupações referentes à dimensão tarefa relacionam-se com o planejamento, organização e execução das atividades didático-pedagógicas que são atribuídas ao professor durante seu expediente de trabalho. Nesse sentido, os professores demonstraram preocupações com: planejamento (E1/C2/R1/R2/R3/ R4/M1/M4), avaliação (E1/E2/E3/C1/C4/D1/D2/D3/ D4/R1/R2/R3/R4), número de alunos por turma (E1/E2/ $\mathrm{E} 3 / \mathrm{E} 4 / \mathrm{C} 1 / \mathrm{C} 2 / \mathrm{C} 3 / \mathrm{C} 4 / \mathrm{D} 1 / \mathrm{D} 2 / \mathrm{D} 3 / \mathrm{D} 4 / \mathrm{R} 3)$, infraestrutura e materiais (E1/E2/E3/C1/C2/C3/C4/D2/D4/R1/R2/R3/ R4/M1/M2/M3/M4) e questões burocráticas (D1/D4/ R1/R3/M4) (Quadro 3).

Nos resultados destacaram-se as preocupações com a infraestrutura e falta de materiais, as quais acometem os professores do início ao fim da carreira. As preocupações referentes ao planejamento, à avaliação e o número de alunos por turma afetaram quase todos os ciclos de desenvolvimento profissional, exceto o ciclo de Maturidade. Por fim, a preocupação com questões burocráticas influência apenas os três últimos ciclos investigados.

Resultados similaridades foram encontrados em duas investigações com professores de EF (Folle e Nascimento, 2011; Trusz, 2016). Contudo, o ciclo de Maturidade na carreira foi o que apresentou menor preocupação com essa dimensão quando comparado com os demais momentos da carreira. Esse fato pode ser explicado pelas características do ciclo, o qual descreve que os docentes possuem experiência e conhecimento tácito suficiente em suas ações pedagógicas (Farias et al., 2018), além de ter declínio progressivo na carreira, preparando o docente para o afastamento da profissão (Sikes, 1985), e maior tempo dedicado a eles mesmos, o que provoca um distanciamento do trabalho (Gonçalves, 2000).
O destaque que a dimensão Tarefa obteve neste estudo pode ser justificado pela especificidade local dos participantes (Costa, 2013; Trusz, 2016), que conforme apresentado no Quadro 1 foram investigados professores da rede municipal e estadual de ensino. Identificou-se durante as entrevistas que a rede estadual de ensino apresentava algumas adversidades quando comparada com a rede municipal. Essas diferenças podem ser exemplificadas na realidade vivenciada pelos professores da rede estadual nas questões associadas ao planejamento, o qual não apresenta uma estrutura prévia ou organização alinhada e única e também nos escassos e precários materiais e locais para a prática das aulas. Por outro lado, a rede municipal possui um planejamento estabelecido para todos os professores desde o início do ano letivo, bem como uma melhor organização de espaço e materiais para ministrar suas aulas.

A preocupação em relação ao número de alunos por turma merece destaque por acometer a maioria dos professores investigados. Essa preocupação foge da responsabilidade e do controle da escola e são consideradas políticas macro organizacionais, as quais independem dos professores e são de responsabilidade das instâncias superiores como Secretarias de Educação e Núcleos Regionais de Ensino (Both, 2011), sendo que tais preocupações interferem de forma direta e indireta na ação docente (Costa et al., 2013).

\section{DIMENSÃO IMPACTO DA TAREFA}

As preocupações docentes sobre o Impacto da Tarefa que estavam presentes em todos os ciclos de desenvolvimento profissional foram: resultado do ensino para o aluno (E3/C1/C3/C4/D2/R4/M1/M2); identificação de dificuldades/necessidades de aprendizagem (E1/E2/ E3/E4/C1/C2/D1/D2/D3/R1/R2/R3/R4/M1/M2/M3/ M4); motivação dos alunos (E1/E2/E3/E4/C1/C2/C3/C4/ D1/D2/D3/D4/R2/R3/R4/M1/M2/M3/M4). Entretanto, a preocupação referente à falta da individualização do ensino foi constatada apenas no ciclo de Maturidade (M2/M3/M4) (Quadro 4).

As preocupações associadas ao Impacto da Tarefa se sobressaíram, como apresentado em estudos semelhantes (Conkle, 1996; Zounhia e Hatziharistos, 2005; Costa, 2013; Trusz, 2016). Assim, percebe-se que as preocupações referentes a sanar as necessidades e dificuldades dos alunos, e perceber que o ensino impacta na vida dos discentes preocupam e influenciam no agir pedagógico dos professores.

É importante destacar que houve a diminuição de preocupação com o Impacto da Tarefa no ciclo que corresponde a Renovação, evidenciado de forma mais pontual entre os homens, que conforme apresentado no Quadro 1 é o único ciclo que consta com dois homens como participantes. Os poucos fatores relacionados à preocupação identificados entre os homens também foram evidenciados em outros estudos (Zounhia e Hatziharistos, 2005; Trusz, 2016). Isso pode estar 
Quadro 3. Indicadores da dimensão Tarefa.

\begin{tabular}{|c|c|c|}
\hline Indicadores & Ciclos & Relatos \\
\hline \multirow{5}{*}{ Planejamento } & Entrada & $\begin{array}{l}\text { A preocupação é relacionada ao planejamento, se vai dar tempo de aplicar, se não } \\
\text { vai dar tempo, porque há períodos que o planejamento é muito grande (E1). }\end{array}$ \\
\hline & Consolidação & $\begin{array}{l}\text { No estado, o planejamento é muito falho. Se faz um planejamento anual, somente } \\
\text { os conteúdos, não precisa detalhar as atividades... está lá para "inglês ver". (C2). }\end{array}$ \\
\hline & Diversificação & 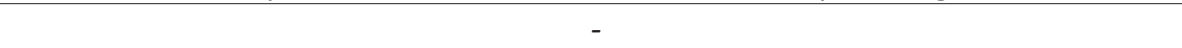 \\
\hline & Renovação & $\begin{array}{l}\text { Aqui na escola para melhoria do nosso próprio trabalho conseguimos sistematizar } \\
\text { o conteúdo do primeiro, do segundo e do terceiro trimestre. Infelizmente a EF não } \\
\text { tem essa sistematização... (R4) }\end{array}$ \\
\hline & Maturidade & $\begin{array}{l}\text { Até nós professores aqui da escola não temos sequência de conteúdos, porque } \\
\text { cada um tem um pensamento. Então teria que ter um planejamento sequencial pra } \\
\text { todos, facilitaria o nosso trabalho (M1). }\end{array}$ \\
\hline \multirow{5}{*}{ Avaliação } & Entrada & $\begin{array}{l}\text { A avaliação não tem um critério para os professores de EF, não é discutido. Não é } \\
\text { tentar melhorar a avaliação por si só, abstratamente desvinculado do ensino da EF } \\
\text { (E3). }\end{array}$ \\
\hline & Consolidação & $\begin{array}{l}\text { A avaliação fica a cargo do professor, ele pode avaliar pela prática, pela escrita. } \\
\text { Eu vejo que cada professor cria o seu método de avaliação. Mas a avaliação [...] } \\
\text { poderia ter alguma coisa assim, algo mais especifica voltado para a EF (C1). }\end{array}$ \\
\hline & Diversificação & $\begin{array}{l}\text { Eu particularmente acho que a avaliação é meio furada. É o sistema que manda e } \\
\text { eu preciso atribuir uma nota, então você acaba entrando no barco junto (D4). }\end{array}$ \\
\hline & Renovação & $\begin{array}{l}\text { Isso aí é uma história..., acho que não vamos conseguir resolver [risos], porque é } \\
\text { um problema que tem desde quando eu entrei na } E F(R 1) \text {. }\end{array}$ \\
\hline & Maturidade & 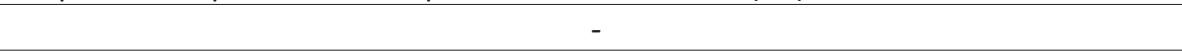 \\
\hline \multirow{5}{*}{$\begin{array}{l}\text { Número de alunos } \\
\text { por turma }\end{array}$} & Entrada & $\begin{array}{l}\text { Uma turma de } 33 \text { alunos, há conversa, há indisciplina, é complicado, é desgastante, } \\
\text { você sai acabada, de tanto pedir, você tá dando a aula e tá toda hora tendo que } \\
\text { chamar a atenção... Você entra numa turma menor, eles já mantem um foco, } \\
\text { conseguem manter concentração (E4). }\end{array}$ \\
\hline & Consolidação & $\begin{array}{l}\text { Eu sei que não é uma questão que nós professores possamos resolver. É mais } \\
\text { uma questão administrativa, burocrática e de infraestrutura. Pra mim é um dos } \\
\text { principais empecilhos para a aprendizagem. [...] Aqui eu dou aula em } 9 \text { turmas, } 30 \\
\text { pessoas cada turma. A gente "malemá" sabe o nome de cada um (C2). }\end{array}$ \\
\hline & Diversificação & $\begin{array}{l}\text { Muito não só pela quantidade, mas principalmente pela estrutura física que } \\
\text { geralmente são salas pequenas que comportam } 25 \text { alunos e nós temos que colocar } \\
\text { de } 30 \text { a } 35 \text { (D3). }\end{array}$ \\
\hline & Renovação & $\begin{array}{l}\text { Difícil hein? Muitas vezes o objetivo da gente não é alcançado, a gente passa certo } \\
\text { estresse e vai levando conforme a gente consegue. Muitas vezes a gente deixa até } \\
\text { de trabalhar algumas aulas porque a dispersão é muito grande (R3). }\end{array}$ \\
\hline & Maturidade & 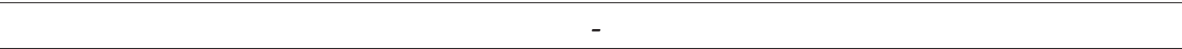 \\
\hline \multirow{5}{*}{$\begin{array}{l}\text { Infraestrutura e } \\
\text { Materiais }\end{array}$} & Entrada & $\begin{array}{l}\text { A infraestrutura não é boa e também há falta de materiais. São materiais caros e } \\
\text { é difícil comprar coisa básica, ainda mais material de EF que é considerado caro e } \\
\text { supérfluo (E2). }\end{array}$ \\
\hline & Consolidação & $\begin{array}{l}\text { Incomoda bastante, porque às vezes planeja uma atividade, e naquela escola não } \\
\text { tem o material necessário para realizar, ai você tenta adaptar e não tem material } \\
\text { necessário para adaptar (C1). }\end{array}$ \\
\hline & Diversificação & $\begin{array}{l}\text { A falta de material, porque a gente poderia trabalhar muitas outras atividades... } \\
\text { (D4). }\end{array}$ \\
\hline & Renovação & $\begin{array}{l}\text { Temos apenas uma quadra coberta, mas em dias de chuva não é possível utiliza-la, } \\
\text { eu vou tentando me adaptar, mas se eu tivesse mais espaço eu seria uma } \\
\text { profissional mais realizada [risos] (R3). }\end{array}$ \\
\hline & Maturidade & $\begin{array}{l}\text { Porque a EF tem que dar aula em uma quadra que muitas vezes não é limpa, não é } \\
\text { varrida, não é lavada? (M4). }\end{array}$ \\
\hline \multirow{5}{*}{$\begin{array}{l}\text { Questões } \\
\text { Burocráticas }\end{array}$} & Entrada & - \\
\hline & Consolidação & - \\
\hline & Diversificação & $\begin{array}{l}\text { A burocracia na prefeitura é bem "amarradinha", tem bastantes obstáculos em } \\
\text { relação ao plano de cargos e salários (C1). }\end{array}$ \\
\hline & Renovação & $\begin{array}{l}\text { São questões que não competem à organização da escola, são atribuições que vem } \\
\text { de cima, nós estamos acabando de sair de um final de trimestre, então há correção } \\
\text { de provas, entrega de livros, correção de trabalhos, isso daí é bem pesado (R3). }\end{array}$ \\
\hline & Maturidade & $\begin{array}{l}\text { Eu acho que o professor tá cada vez mais soterrado de tarefas, é a tarefa de além } \\
\text { de ele trabalhar o seu conteúdo específico, trabalhar o seu relacionamento com o } \\
\text { aluno. Tem as questões cada vez mais impostas pela questão da burocracia (M4). }\end{array}$ \\
\hline
\end{tabular}

Fonte: Os autores. 
Quadro 4. Indicadores da dimensão Impacto da tarefa.

\begin{tabular}{|c|c|c|}
\hline Indicadores & Ciclos & Exemplos de relatos \\
\hline \multirow{5}{*}{$\begin{array}{l}\text { Resultado do } \\
\text { ensino para o aluno }\end{array}$} & Entrada & $\begin{array}{l}\text { Certo cuidado com questões envolvendo o processo de ensino-aprendizagem do } \\
\text { aluno, se aquele processo está sendo efetivo. Com finalidade de transformá-lo, de } \\
\text { contribuir para sua formação (E3). }\end{array}$ \\
\hline & Consolidação & $\begin{array}{l}\text { Se eu não me preocupasse com isso eu nem daria aula. O objetivo é fazer isso, ter } \\
\text { esse impacto na vida das crianças (C4). }\end{array}$ \\
\hline & Diversificação & $\begin{array}{l}\text { Eu me preocupo principalmente, pensando naquilo que eu aprendi, naquilo que } \\
\text { na função enquanto professor e aquilo que eu quero enquanto educação pra eles } \\
\text { [alunos] (D2). }\end{array}$ \\
\hline & Renovação & $\begin{array}{l}\text { A gente tem a preocupação de formar um aluno que possa sair da escola, e dar } \\
\text { conta da sua qualidade de vida por conta própria (R4). }\end{array}$ \\
\hline & Maturidade & $\begin{array}{l}\text { Você tem que tá preocupado, buscando uma melhor maneira dele [aluno] } \\
\text { realmente mudar o senso crítico, o que ele [aluno] acha, o que que ele [aluno] não } \\
\text { acha, porque tem que ter uma mudança (M1). }\end{array}$ \\
\hline \multirow{5}{*}{$\begin{array}{l}\text { Identificação de } \\
\text { dificuldades/ } \\
\text { necessidades de } \\
\text { aprendizagem }\end{array}$} & Entrada & $\begin{array}{l}\text { Eu consigo identificar as dificuldades de aprendizagem. E, o principal, o } \\
\text { impedimento dos alunos para a aprendizagem é a formação que eles tem, a } \\
\text { educação que eles tiveram antes da escola (E3). }\end{array}$ \\
\hline & Consolidação & $\begin{array}{l}\text { Eu sempre procuro abordar os conteúdos de uma forma bastante clara pra eles. } \\
\text { Procuro montar a aula de uma forma de acordo com o perfil da turma que eu sei } \\
\text { que eles vão responder de uma forma efetiva (C2). }\end{array}$ \\
\hline & Diversificação & $\begin{array}{l}\text { Preocupo com a carência dos alunos, até porque hoje é uma grande maioria dentro } \\
\text { da sala de aula que tem problemas (D4). }\end{array}$ \\
\hline & Renovação & $\begin{array}{l}\text { Eu vou dizer uma coisa, as maiores complicações em relação à aprendizagem estão } \\
\text { no sentido emocional desses alunos (R4). }\end{array}$ \\
\hline & Maturidade & $\begin{array}{l}\text { As dificuldades são motoras, que a gente já identifica logo quando começa } \\
\text { dar aula, você começa a ver aquela criança a correr, a andar, você já começa a } \\
\text { identificar. (M4). }\end{array}$ \\
\hline \multirow{5}{*}{$\begin{array}{l}\text { Motivação dos } \\
\quad \text { alunos }\end{array}$} & Entrada & $\begin{array}{l}\text { A motivação é importante pra tudo na vida, não é possível você desenvolver uma } \\
\text { aula espontânea, que flui, que você consiga ensinar, sem que os alunos estejam } \\
\text { motivados, e pra isso você tem que se adequar (E3). }\end{array}$ \\
\hline & Consolidação & $\begin{array}{l}\text { Às vezes você faz de tudo e daí você vê que o problema não está na sua } \\
\text { metodologia, na sua forma de ensinar, o problema é que o aluno não quer } \\
\text { aprender (C2). }\end{array}$ \\
\hline & Diversificação & $\begin{array}{l}\text { Então, não adianta nada eu me esforçar, chamar a atenção do aluno, se ele não } \\
\text { quer. O aluno vem desmotivado hoje pra escola, ele já vem achando que aqui } \\
\text { é um lugar ruim, é uma coisa chata, é um ambiente que ele não vai encontrar } \\
\text { oportunidades (D4). }\end{array}$ \\
\hline & Renovação & $\begin{array}{l}\text { A gente faz de tudo. Pressão, faz chantagem, tenta incentivar. Nem sempre dá } \\
\text { certo. Eles vêm muito mal, eles só pensam em brincar. Acham que EF é brincar e, } \\
\text { não querem aprender nada (R2). }\end{array}$ \\
\hline & Maturidade & $\begin{array}{l}\text { O aluno que não participa, que se mostra desinteressado eu tenho que fazer ele } \\
\text { participar da minha aula. Que estratégia eu tenho: a troca de metodologias, a } \\
\text { mudança no desenvolvimento das minhas aulas (M3). }\end{array}$ \\
\hline \multirow{5}{*}{$\begin{array}{l}\text { Falta do Ensino } \\
\text { Individualizado } \\
\text { com o aluno }\end{array}$} & Entrada & - \\
\hline & Consolidação & - \\
\hline & Diversificação & - \\
\hline & Renovação & - \\
\hline & Maturidade & $\begin{array}{l}\text { Se a educação é dita importante como que você irá dar algo de qualidade em } 50 \\
\text { minutos para } 30 \text { cabeças? O atendimento individualizado fica completamente } \\
\text { deteriorado e comprometido (M2). }\end{array}$ \\
\hline
\end{tabular}

Fonte: Os autores.

associado à jornada de trabalho que as mulheres desempenham diariamente e que contemplam a rotina familiar, além de todos os percalços que envolvem o trabalho, o que pode ocasionar no aumento das preocupações (Vieira et al., 2018).

Além disso, no ciclo de Maturidade foi apresentado maior número de citações de preocupação com a dimensão Impacto da Tarefa. Este fato pode ser relacionado ao encantamento dos professores deste ciclo com o magistério e valorização da docência, pois são defensores da causa docente e buscam a renovação das ações pedagógicas (Farias et al., 2018). Porém, a preocupação vinculada à falta de um ensino individualizado ao aluno foi reportada apenas entre os professores mais experientes, o que pode estar vinculado à maior vivência das ações pedagógicas dos professores, o que provocou preocupações referentes às necessidades dos alunos. De fato, nesse momento da carreira alguns professores ainda se preocupam com seu local de trabalho e alunos (Gonçalves, 2000). 


\section{CONCLUSÕES}

Em relação às preocupações analisadas nesta pesquisa observou-se que a Teoria das Preocupações não se apresenta com a mesma sequência e intensidade como é reportada na literatura. As dimensões de preocupações apresentaram alterações no decorrer dos ciclos de desenvolvimento profissional. Desta forma, o endereço social e/ou o contexto histórico-social no qual a pesquisa foi realizada podem ser fatores significativos para os resultados encontrados.

$\mathrm{Na}$ análise da dimensão Consigo destacou-se que o ciclo de Entrada apresentou maiores preocupações. Contudo, é importante ressaltar que as autopreocupações não desaparecem no decorrer dos ciclos, apenas diminuíram a intensidade das inquietações sobre esta temática.

As preocupações frente à dimensão Tarefa apresentaram ser fortes entre todos os participantes desse estudo. De fato, questões macro e micro organizacionais podem interferir nas preocupações desta dimensão. As questões macro organizacionais que se reportam à falta de investimentos e descaso com a educação, interferem nas preocupações e não estão no controle das ações dos professores. O mesmo acontece com as questões de ordem micro organizacionais, que reportam os acontecimentos do ambiente de trabalho, que podem envolver a direção, equipe pedagógica, outros professores das unidades de ensino.

Os docentes também evidenciaram preocupações desde o início da carreira com a dimensão Impacto da Tarefa. Percebeu-se nessa dimensão uma mudança quando comparada a teoria de Fuller (1969), isso porque os professores em início da carreira apresentaram grandes preocupações com o impacto de suas ações mediados pelo contexto social dos alunos.

Assim, conclui-se que os professores estavam mais preocupados com o resultado e com as tarefas que envolvem sua ação pedagógica do que com a sua sobrevivência no ambiente de trabalho. Entretanto, estudos com outros profissionais que trabalham no ambiente escolar podem possibilitar uma visão mais ampla, o que poderia enriquecer as evidências das investigações. No intuito de amenizar as preocupações que acometem os professores no decorrer da carreira, propõe-se que a socialização profissional seja realizada com maior ênfase durante a formação inicial, por meio dos estágios, do gradativo aumento das práticas de ensino, dos programas que fomentem a inserção do acadêmico nas escolas, e assim auxiliem a atenuar o choque com a realidade que acomete os professores nos primeiros anos de docência. Além disso, seria importante inserir ações de formação continuada que ajudem a minimizar o impacto das preocupações dos professores nos demais ciclos da carreira docente.

\section{FINANCIAMENTO}

O presente trabalho não contou com apoio financeiro de nenhuma natureza para sua realização.

\section{CONFLITOS DE INTERESSE}

Os autores declaram não haver conflitos de interesse.

\section{REFERÊNCIAS}

Bardin L. Análise de conteúdo. São Paulo: Editora Persona; 1977.

Both J. Bem-estar do trabalhador docente em Educação Física da região sul do Brasil [tese]. Florianópolis: Universidade Federal de Santa Catarina; 2011.

Conkle T. Inservice physical educators' stages of concerns: a test of fuller's model and the TCQ-PE. Phys Educator. 1996;53(3):122-32.

Costa BO, Henrique J, Ferreira J. Percepções pessoais de uma professora de educação física em início de carreira. Rev Mackenzie de Educação Física e Esporte. 2013;12(1):17386.

Costa BO. Preocupações pedagógicas e desenvolvimento profissional em Educação Física: passo ou descompasso? [dissertação]. Seropédica: Universidade Federal Rural do Rio de Janeiro; 2013.

Farias GO, Batista PMF, Graça A, Nascimento JV. Ciclos da trajetória profissional na carreira docente em educação física. Movimento. 2018;24(2):441-54. http://dx.doi. org/10.22456/1982-8918.75045.

Favatto NC, Both J. Preocupações dos professores de educação física no início da carreira docente. Motrivivência. 2019;31(58):1-17. http://dx.doi.org/10.5007/2175$8042.2019 \mathrm{e} 56655$.

Ferreira MAM. Ciclo de vida, desenvolvimento profissional e gestão escolar: uma abordagem bibliográfica [dissertação]. Lisboa: Universidade Aberta; 2008.

Folle A, Farias GO, Boscatto JD, Nascimento JV. Construção da carreira docente em educação física: escolhas, trajetórias e perspectivas. Movimento. 2008;15(1):25-49. http://dx.doi. org/10.22456/1982-8918.3014.

Folle A, Nascimento JV. Preocupações ao longo da carreira docente: estudos de caso com professores de educação física do magistério público estadual. Rev Bras Ciênc Esporte. 2011;33(4):841-56. http://dx.doi.org/10.1590/ S0101-32892011000400004.

Fuller F, Bown O. Becoming a teacher. In: Ryan K, editor. Teacher education: yearbook of the National Society for the Study of Education. Chicago: University of Chicago Press, 1975. p.25-52.

Fuller F. Concerns of teachers: a developmental conceptualization. Am Educ Res J. 1969;6(2):207-26. http://dx.doi.org/10.3102/00028312006002207.

Gonçalves JA. A carreira das professoras do ensino primário. In: Nóvoa A, editor. A vida de professor. 2. ed. Porto: Porto Editora; 2000. p. 141-70.

Huberman M. O ciclo de vida profissional dos professores. In: Nóvoa A, editor. Vidas de professores. 2. ed. Porto: Porto Editora; 2000. p. 31-61.

Nascimento JV, Graça AA. Evolução da percepção de competência profissional de professores de Educação Física ao longo de sua carreira docente. In VI Congreso de Educación Física e 
Ciencias do Deporte dos Países de Lingua Portuguesa e VII Congreso Galego de Edicación Física: livro de resumos; 1998; La Coruña. Resumos. Porto: Universidade do Porto; 1998.

Sikes P. The life cycle of the teacher. In: Balls SJ, Goodson IF, editores. Teachers lives and careers. London: The Falmer Press; 1985. p. 103-12.

Tardif M. Saberes profissionais dos professores e conhecimentos universitários: elementos para uma epistemologia prática profissional dos professores e suas consequências em relação a formação para o magistério. Rev Bras Educ. 2000;13:5-24.

Tankersley AA. Discovering curriculum concerns of beginning early childhood teachers. Child Educ. 2010;86(5):293-7. http://dx.doi.org/10.1080/00094056.2010.10521411.
Trusz RD. Preocupações de Professores de Educação Física de Balneário Camboriú [dissertação]. Florianópolis: Universidade Federal de Santa Catarina; 2016.

Vieira SV, Beuttemmuller LJ, Both J. Preocupações de professores de educação física conforme os ciclos de desenvolvimento profissional e características sociodemográficas. J Phys Educ. 2018;29(1):1-9. http:// dx.doi.org/10.4025/jphyseduc.v28i1.2924.

Wendt JC, Bain LL. Concerns of Preservice and Inservice Physical Educators. J Teach Phys Educ. 1989;8(2):177-80. http:// dx.doi.org/10.1123/jtpe.8.2.177.

Zounhia K, Hatziharistos D. Physical education students teachers' rapport with cooperating teachers: rapport relation with teaching concerns. Stud Phys Cult Tour. $2005 ; 12(1)$. 